Available online at https://jurnal.stmikroyal.ac.id/index.php/jurdimas

\title{
PEMANFAATAN SISTEM INFORMASI GEREJA GKPI JEMAAT KHUSUS PERUMNAS II MANDALA BERBASIS WEB PADA ERA REVOLUSI INDUSTRI 4.0
}

\author{
Murni Marbun ${ }^{1 *}$, Nafasansono Harefa ${ }^{1}$ \\ ${ }^{1}$ Teknik Informatika, STMIK Pelita Nusantara Medan \\ email: dimpleflorence@yahoo.co.id
}

\begin{abstract}
In response to the Industrial Revolution 4.0 era, where information technology has become the basis of human life, houses of worship can also take advantage of advances in information technology to provide optimal services to their congregants. Community service activities aim to build the website of the GKPI Jemaat Khusus Perumnas II Mandala Church. The method or stage of implementation of the service starts from the preparation stage, the implementation phase, the implementation phase and the report preparation stage. The results of the implementation of the service is the availability of a website-based information system in the Church of GKPI Jemaat Khusus Perumnas II Mandala that can be utilized in providing services in the form of delivering news information, announcements and announcements of church activities that have been carried out or will be carried out. The information system is built based on a website that displays Home, Profile, Management, Citizenship, Services/Services, News and Gallery information.
\end{abstract}

Keywords: information systems, websites, industrial revolution 4.0

\begin{abstract}
Abstrak: Untuk merespon era Revolusi Industri 4.0, dimana teknologi informasi telah menjadi basis dalam kehidupan manusia, rumah ibadah juga dapat memanfaatkan kemajuan teknologi informasi untuk memberikan pelayanan yang optimal kepada jemaatnya. Kegiatan pengabdian kepada masyarakat bertujuan untuk membangun website Gereja GKPI Jemaat Khusus Perumnas II Mandala. Metode atau tahapan pelaksanaan pengabdian dimulai dari tahap persiapan, tahap pelaksanaan, tahap implementasi dan tahap pembuatan laporan. Hasil dari pelaksanaan pengabdian adalah tersedianya system informasi berbasis website di Gereja GKPI Jemaat Khusus Perumnas II Mandala yang dapat dimanfaatkan dalam memberikan pelayanan dalam bentuk penyampaian informasi berita, pengumuman dan pemberitahuan aktifitas-aktifitas kegiatan gereja yang telah dilaksanakan maupun yang akan dilaksanakan. Sistem informasi dibangun berbasis website yang menampilkan informasi Home, Profil, Pengurus, Pembinaan Warga, Tata Ibadah/Layanan, Berita dan Galeri.
\end{abstract}

Kata kunci: sistem informasi, website, revolusi industri 4.0 
Available online at https://jurnal.stmikroyal.ac.id/index.php/jurdimas

\section{PENDAHULUAN}

Perubahan dunia kini tengah memasuki era revolusi industri 4.0 atau revolusi industri dunia keempat dimana teknologi informasi telah menjadi basis dalam kehidupan manusia. Istilah Industri 4.0 lahir dari ide revolusi industri ke empat. Angka empat pada istilah Industri 4.0 merujuk pada revolusi yang ke empat. Industri 4.0 merupakan fenomena yang unik jika dibandingkan dengan tiga revolusi industri yang mendahuluinya (Prasetyo \& Sutopo, 2018).

Era revolusi teknologi yang terjadi sekarang ini, secara fundamental akan mengubah cara hidup, cara bekerja, pola berpikir dan cara bekerja satu sama lain dalam lingkup domestik maupun mondial (Rodin, 2019).

Menurut Muhammad Yahya dalam Pidato Pengukuhan Penerimaan Jabatan Professor Tetap dalam Bidang Ilmu Pendidikan Kejuruan (2018), revolusi Industri 4.0 secara fundamental mengakibatkan berubahnya cara manusia berpikir, hidup, dan berhubungan satu dengan yang lain.

Rumah ibadah adalah salah satu pemangku kepentingan yang merespon perubahan revolusi industry 4.0. Salah satu perubahan adalah pemanfaatan kemajuan teknologi informasi. Kemajuan teknologi komputer dapat mendukung pemrosesan data dan informasi. Banyak gereja yang dapat memanfaatkan kemajuan teknologi dimana salah satunya GKPI Palmerah Jambi yang telah merancang sistem pengolahan data Jemaat Berbasis Web (Sagala et al., 2018).

Pelayanan yang optimal di Gereja GKPI Jemaat Khusus Perumnas II Mandala dalam penyampaian informasi dapat diwujudkan dengan membangun suatu sistem informasi berbasis website.
Perancangan sistem informasi adalah kegiatan yang merancang dan mengolah data menjadi informasi yang dibutuhkan (Sadewa \& Siahaan, 2016). Perancangan dimulai dari observasi, membuat rancangan sistem informasi hingga pembuatan kode program (Oktasari \& Kurniadi, 2019).

Website yang dibangun dapat memberikan kemudahan dalam aktifitas pelayanan gereja seperti, menyampaikan pengumuman, menyampaikan tata ibadah, mengupload foto-foto kegiatan, dll. Website (situs web) merupakan kumpulan dari halaman-halaman web yang berhubungan dengan file-file lain yang terkait (Fahmi et al., 2020). Halaman utama website dikenal dengan sebutan halaman home. Home adalah sebuah halaman yang pertama kali dilihat ketika seseorang mengunjungi website tersebut. Dari halaman home, pengujung dapat mengklik hyperlink untuk pindah kehalaman halaman lain.

\section{METODE}

Program PkM dilaksanakan di Gereja GKPI Jemaat Khusus Perumanas II yang berlokasi di Jl. Tiung Raya Ujung Perumnas II Mandala. Metode atau tahapan pelaksanaan program $\mathrm{PkM}$ terdiri dari:

1. Tahap Persiapan yaitu menjalin kerjasama, pengumpulan data dan pembelian peralatan dan bahan yang dibutuhkan

2. Tahap Pelaksanaan yaitu mela-kukan sosialisasi kegiatan dan pembuatan website.

3. Tahap Implementasi yaitu memposting website yang sudah di bangun dan memberikan sosialisasi website dan pelatihan bagi operator gereja yang ditunjuk. 
Available online at https://jurnal.stmikroyal.ac.id/index.php/jurdimas

\section{PEMBAHASAN}

Pelaksanaan PkM dimulai dengan terjalinnya kerjasama dengan mitra yaitu Gereja GKPI Jemaat Khusus Perumnas II Mandala. Kerjasama ditandai dengan balasan surat dari mitra dalam bentuk surat kesediaan sebagai mitra pada program PkM.

Kegiatan selanjutnya adalah sosialisasi untuk menyampaikan informasi tentang website yang akan dibangun dan kebutuhan-kebutuahan lain yang berkaitan dengan data data yang dibutuhkan

Data dan informasi yang dibutuhkan terdiri dari:

1. Profile Gereja terdiri dari:
a. Sejarah Gereja
b. Tata Gereja GKPI
c. Peraturan Rumah Tangga
d. Visi dan Misi
e. Logo GKPI

2. Pengurus terdiri dari:
a. Pendeta
b. PHJ
c. Seksi-Seksi
d. Penasehat
e. Pengawas Harta Benda/Keuangan (PHB)
f. Penatua dan Pelayan Rohani

3. Pembinaan Warga terdiri dari:
a. Sekolah Minggu
b. Pemuda/Pemudi dan Remaja
c. Tim Musik
d. Pos PI Jermal
e. Kaum Perempuan
f. Kaum Pria
g. Kaum Lansia
h. Koor

4. Tata Ibadah terdiri dari:
a. Kebaktian Hari Minggu
b. Kebaktian Sektor
c. Kebaktian Kaum Perempuan
d. Kebaktian Kaum Lansia
e. Kebaktian Pemuda/Pemudi dan Remaja
f. Kebaktian Penatua
g. Layanan Ibadah

5. Berita, Foto-Foto dan video Kegiatan yang telah dilakukan

Adapun tampilan website yang telah dibangun sebagai berikut:

\section{Tampilan Home}

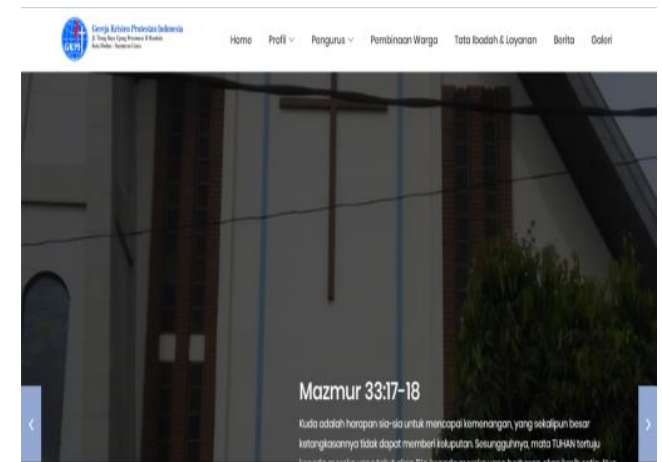

Gambar 1. Tampilan Home

Gambar 1 adalah tampilan Home yang merupakan tampilan utama ketika website diakses melalui url: gkpimandala.org. Pada tampilan Home terdiri dari Home, Profile, Pengurus, Pembinaan Warga, Tata Ibadah/Layanan, Berita dan Galeri.

\section{Tampilan Profil}

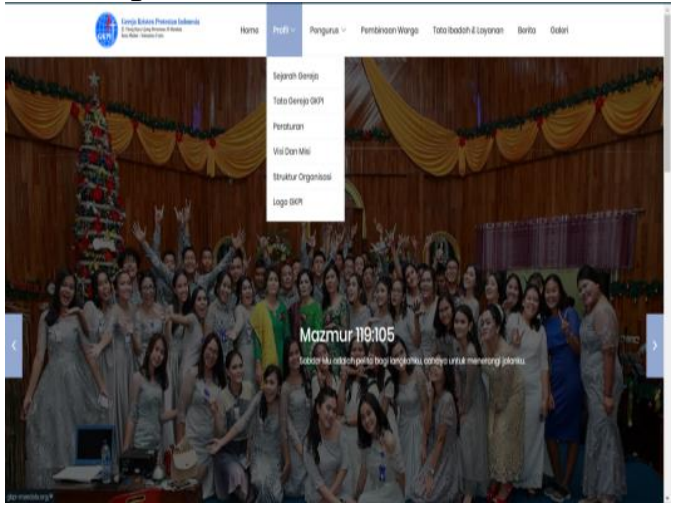

Gambar 2. Tampilan Profil

Gambar 2 adalah tampilan Profile yang menampilkan informasi tentang Sejarah Gereja, Tata Gereja GKPI, Peraturan Rumah Tangga, Visi dan Misi, Logo GKPI 
Available online at https://jurnal.stmikroyal.ac.id/index.php/jurdimas

3. Tampilan Pengurus

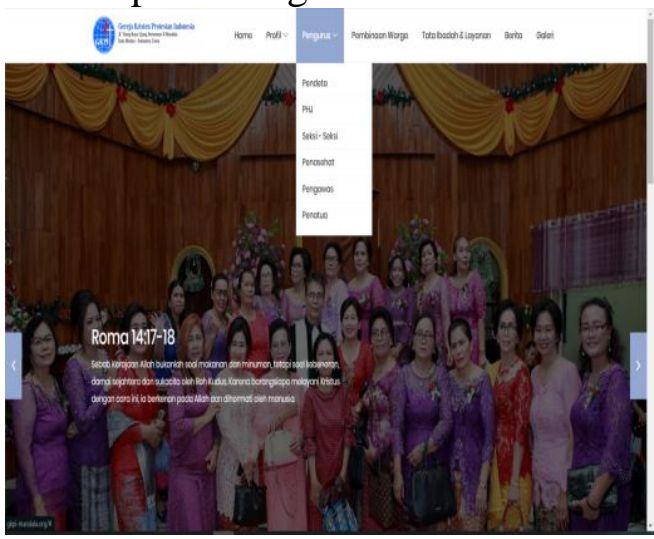

Gambar 3. Tampilan Pengurus Gereja

Gambar 3 adalah tampilan Pengurus yang menampilkan informasi tentang Pendeta, PHJ, Seksi-Seksi, Penasehat, Pengawas Harta Benda/Keuangan (PHB), Penatua dan Pelayan Rohani Pendeta, PHJ, Seksi-Seksi, Penasehat, Pengawas Harta Benda/Keuangan (PHB), Penatua dan Pelayan Rohani.

\section{Tampilan Pembinaan Warga}
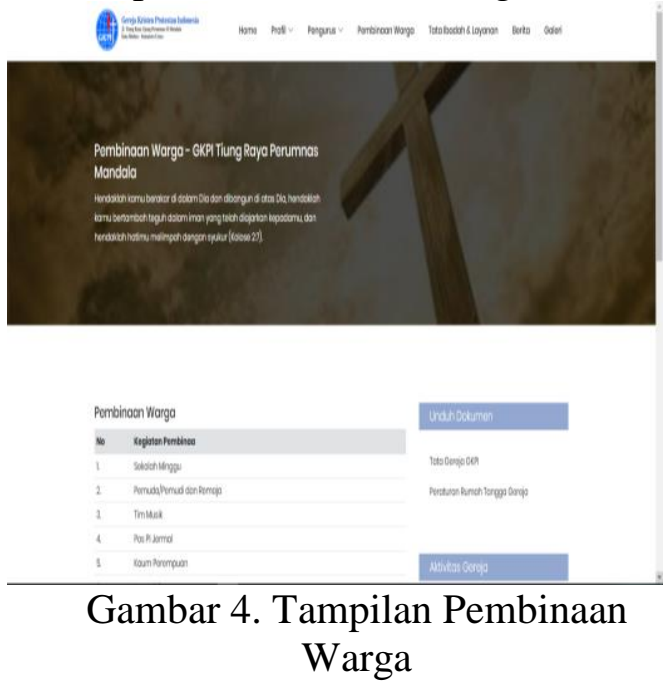

Gambar 4 adalah tampilan Pembinaan warga yang menampilkan informasi tentang kegiatan yang dibina oleh gereja yang terdiri dari Sekolah Minggu, Pemuda/Pemudi dan Remaja, Tim Musik, Pos PI Jermal, Kaum Perempuan,
Kaum Pria, Kaum Lansia dan Seksi Koor.

5. Tampilan Tata Ibadah/Layanan
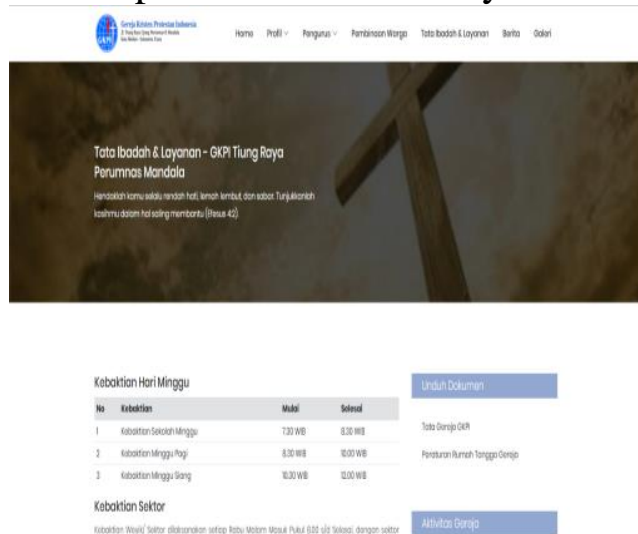

Gambar 5. Tata Ibadah/Layanan

Gambar 5 adalah tampilan Tata Ibadah/Layanan yang menampilkan jadwal ibadah yang terdiri dari ibadah Sekolah Minggu, ibadah Bahasa Indonesia dan Ibadah bahasa daerah.

6. Tampilan Berita dan Galeri
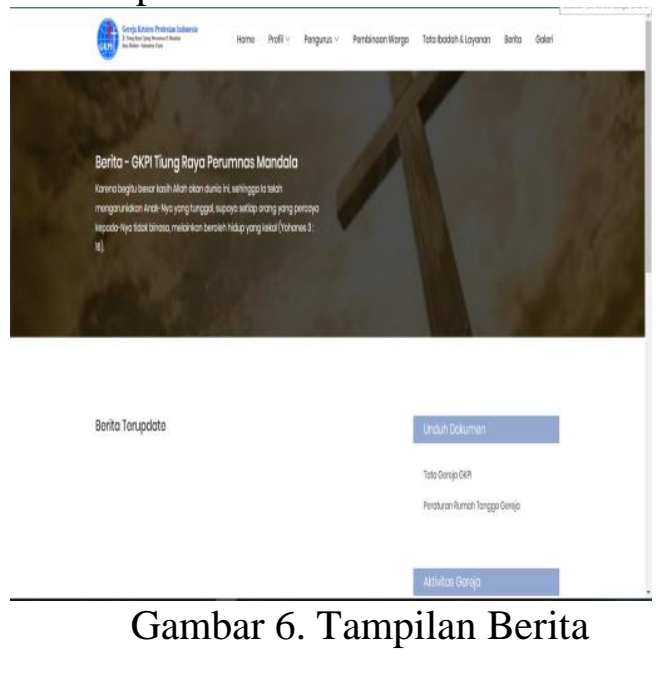

Gambar 6 adalah tampilan Berita dan Galeri yang menampilkan informasi berita-berita yang disampaikan kepada jemaat, baik dalam bentuk pengumumuman maupun informasi-informasi dari warta jemaat. Informasi yang ditampilkan pada Galeri adalah informasi dalam 
Available online at https://jurnal.stmikroyal.ac.id/index.php/jurdimas

bentuk foto dan video dari kegiatan kegiatan jemaat.

\section{Sosialisasi Website}

Website yang telah dibangun dan diposting pada url: gkpi-mandala.org di sosialisasikan kepada pengurus gereja dan memberikan pelatihan pengelolaan website kepada operator. Gambar 7 adalah kegiatan sosialisasi website untuk menjelaskan tampilan-tampilan pada website dan bagaimana mengakses website. Gambar 8 adalah kegiatan pelatihan kepada operator dilakukan untuk menjelaskan bagaimana website dikelola agar informasi informasi dapat disampaikan dengan baik kepada jemaat atau masyarakat.

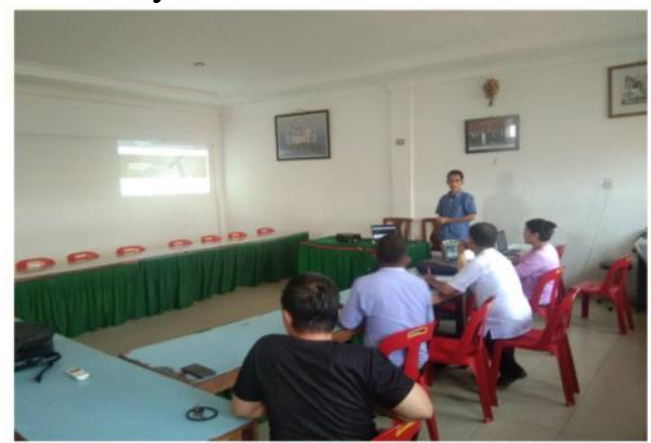

Gambar 7. Sosialisasi Website

Website digunakan untuk memberikan Informasi dalam bentuk berita, gambar, video dan pengumumanpengumuman kepada jemaat.

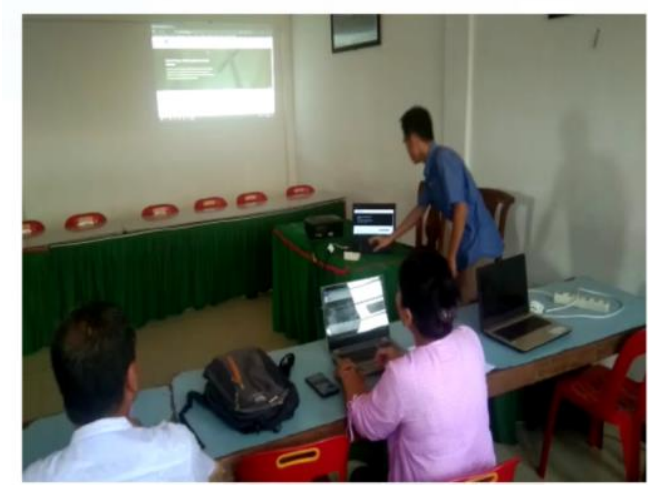

Gambar 8. Pelatihan Pengeloaan Website

\section{SIMPULAN}

Berdasarkan kegiatan pengabdian yang telah dilaksanakan, maka dapat di simpulkan bahwa system informasi berbasis website yang telah dibangun sangat bermanfaat bagi Gereja GKPI Jemaat Khusus Perumnas II Mandala, terutama bagi pengurus harian gereja yang bertugas menyediakan dan menyampaikan informasi yang dibutuhkan jemaat. Informasi dapat diperoleh dengan cepat dengan mengakses website tersebut. Hasil dari kegiatan PkM ini adalah sebuah website yang telah diimplementasikan oleh pengurus Gereja GKPI Jemaat Khusus Perumnas II Mandala.

\section{UCAPAN TERIMA KASIH}

Terimakasih diucapkan kepada STMIK Pelita Nusantara Medan yang telah memberikan dukungan dana dan kepada pimpinan dan pengurus harian gereja GKPI Jemaat Khusus Perumnas II Mandala yang telah bersedia menjadi mitra untuk program $\mathrm{PkM}$ ini.

\section{DAFTAR PUSTAKA}

Fahmi, M. I., Kifti, W. M., \& Marpaung, N. (2020). PEMANFAATAN WEBSITE SEBAGAI MEDIA INFORMASI PADA POLSEK PORSEA KABUPATEN TOBA SAMOSIR M. Irfan Fahmi* 1, Wan Mariatul Kifti 1 , Nasrun Marpaung 1. 3(1), 51-54.

Muhammad Yahya, H., \& Pidato Pengukuhan Penerimaan Jabatan Professor Tetap dalam Bidang Ilmu Pendidikan Kejuruan, Me. (2018). ERA INDUSTRI 4.0: TANTANGAN $D A N$ PELUANG 
Available online at https://jurnal.stmikroyal.ac.id/index.php/jurdimas

PERKEMBANGAN PENDIDIKAN KEJURUAN INDONESIA

Disampaikan pada Sidang Terbuka

Luar Biasa Senat Universitas Negeri Makassar Tanggal 14 Maret 2018.

Oktasari, A. J., \& Kurniadi, D. (2019). Kata kunci: Sistem Informasi, Manajemen Kegiatan Mahasiswa, SQL, MVC, Framework Yii2. Jurnal Vokasional Teknik Elektronika Dan Informatika, 7(4).

Prasetyo, H., \& Sutopo, W. (2018). Industri 4.0: Telaah Klasifikasi Aspek Dan Arah Perkembangan Riset.J@ti Undip : Jurnal Teknik Industri, 13(1), 17. https://doi.org/10.14710/jati.13.1.17 $-26$
Rodin, R. (2019). Analisis Kesiapan dan Tantangan Perpustakaan Perguruan Tinggi Islam di Indonesia Menghadapi Era 4 . 0. Media Pustakawan, 26(2), 81-90.

Sadewa, I., \& Siahaan, K. (2016). Analisis Dan Perancangan Sistem Indormasi Unit Kegiatan Mahasiswa (UKM) Berbasis Web Pada Universitas Batanghari. Jurnal Manajemen Sistem Informasi, 2(1), 135-146.

Sagala, D. C., Sadikin, A., \& Irawan, B. (2018). Perancangan Sistem Pengolahan Data Jemaat Berbasis Web Pada Gereja Gkpi Kota Jambi. Journal V-Tech (Vision Technology), 1(2), 14-24. https://doi.org/10.35141/jvt.v1i2.92 